\title{
Muscular glucose metabolism in middle-age trained rats
}

\author{
Ana Carolina Ghezzi ${ }^{1,2} \cdot$ Lucieli Teresa Cambri $^{1,3} \cdot$ José Diego Botezelli $^{1,2}$. \\ Maria Alice Rostom de Mello ${ }^{1}$
}

Received: 3 May 2017 / Accepted: 22 June 2017/Published online: 1 July 2017

(c) Springer-Verlag Italia S.r.l. 2017

\begin{abstract}
Aging decreases the normal organism physiological functions. On the other hand, physical exercise shows health benefits, but little information is known about physical deconditioning at aging. The aim of the present study was to analyze the glucose muscle metabolism in middle-age Wistar rats in response to conditioning and physical deconditioning. The study included three groups: Control (C)—not performed physical training; Trained (T)-performed physical training from 4 to 12 monthsswimming exercise for $1 \mathrm{~h}$ per day, 5 days per week at $80 \%$ of maximal lactate stead state-MLSS; Detrained (D) - performed to physical training from 4 to 8 months and assessed at 12 months (D). Physical training at submaximal intensities induced decreases in body weight (C $588 \pm 71$, T $515 \pm 72$, D $576 \pm 62 \mathrm{~g}$ ), and the weight of mesenteric adipose tissue (C $4399 \pm 643$, T $3007 \pm 811$, D $4085 \pm 540 \mathrm{mg} / \mathrm{g}$ ), and increases in exercise workload in MLSS intensity (C $4.6 \pm 0.4, \quad \mathrm{~T} \quad 5.8 \pm 1.3, \quad \mathrm{D}$ $5.3 \pm 0.4 \%$ body weight), glucose tolerance (C $12314 \pm 1122, \quad \mathrm{~T} \quad 8428 \pm 853, \quad \mathrm{D} \quad 9433 \pm 1200 \mathrm{mg} /$ dL $120 \mathrm{~min}$ ), glycogen deposits (C $0.48 \pm 0.07, \quad \mathrm{~T}$ $0.66 \pm 0.18, \quad \mathrm{D} \quad 0.46 \pm 0.10 \mathrm{mg} / 100 \mathrm{mg}$ ) and glucose uptake by skeletal muscle (C $1.96 \pm 0.54$, T $3.28 \pm 0.53$, D $2.55 \pm 0.35 \mu \mathrm{mol} / \mathrm{g} / \mathrm{h}$ ) in trained animals. Additionally, the improvement in exercise load in MLSS, glucose
\end{abstract}

Ana Carolina Ghezzi

carolghezzi@gmail.com

1 Department of Physical Education, Institute of Biosciences, São Paulo State University (UNESP), AV: 24-A, 1515, Bela Vista, Rio Claro CEP 13506-900, Brazil

2 Campinas State University (UNICAMP), Campinas, Brazil

3 Department of Physical Education, Federal University of Mato Grosso (UFMT), Cuiabá, Brazil tolerance and glucose uptake was maintained after physical detraining. In summary, the physical training promotes alterations in body weight, fat tissue, aerobic capacity and muscular glucose metabolism in middle-age rats. However, only the aerobic capacity and muscular glucose metabolism were maintained after detraining.

Keywords Aging - Maximal lactate steady state (MLSS) · Physical exercise · Glycogen - Glucose uptake

\begin{tabular}{ll}
\multicolumn{2}{l}{ Abbreviations } \\
$V \mathrm{O}_{2}$ max & Maximum oxygen consumption \\
$\mathrm{MLSS}$ & Maximum lactate steady state \\
GLUT & Glucose transporter \\
GTT & Glucose tolerance test \\
ITT & Insulin tolerance test
\end{tabular}

\section{Introduction}

It is already well established in the literature that the aging process causes several changes in human metabolism, such as reduction of aerobic capacity and increase in the prevalence of diseases.

Studies have shown that during the aging process there is a tendency to increase body weight, mainly visceral fat, accompanied by the reduction of lean mass, which is directly correlated with insulin resistance and glucose intolerance [1-4].

This scenario of a global pandemic of obesity has encouraged the use of exercise as a non-medication treatment for various diseases, such as obesity, diabetes mellitus, hypertension, changes in plasma lipids and insulin resistance [4-8]. 
Physical exercise that is performed in a controlled manner (e.g., volume, frequency and intensity) provides several benefits to the organism, including disease control and improvements in aerobic capacity [7, 9]. A systematic program of physical training is expected to improve physical fitness [10].

Aerobic capacity, also known as maximum oxygen consumption $\left(V \mathrm{O}_{2 \max }\right)$, is the maximum amount of oxygen uptake, transport and use during an exercise session for the generation of energy [11]. Improvements in aerobic capacity over time are possible with regular physical exercise, but a decrease in this capacity occurs in response to several factors, including a reduction in physical activity, chronic disease and aging [12-14]. Aerobic capacity is an important parameter for training development and the evaluation of fitness improvement in athletes.

Physical exercise should be practiced in a chronic and controlled manner such that the generated adaptations in aerobic capacity persist. Physical training of a known intensity that is prescribed according to an individual's physical capacity makes the practice of physical exercise safer for individuals. The maximum lactate steady state (MLSS) test, which is the gold standard for determining the transition from predominantly aerobic/anaerobic exercise with a constant load, is often used.

Physical training also produces an increase in muscle glycogen $[10,15,16]$, which is an important substrate for energy generation during exercise. Therefore, an increase in the levels of muscle glycogen increases the available substrates and duration of energy generation, which may determine the duration of aerobic exercise [14, 17, 18].

The increase in skeletal muscle glucose uptake is important for improving glycemia in and normoglycemic and diabetic individuals, and physical exercise increases glucose uptake by voluntary muscles [19-21].

The literature also shows that 5-week physical detraining causes cardiac output and heart rate to return to pretraining values, so the importance of physical exercise is maintained chronically [22]. However, most studies evaluate short and medium periods of physical training, followed by short periods of physical detraining.

The aim of the present study was to analyze the effect of systematic submaximal physical exercise and 4-month physical detraining on aerobic capacity and glucose muscle metabolism in middle-age Wistar rats.

The hypotese of the study was that physical exercise would be able to reduce the declines caused by the aging process in aerobic capacity, glucose metabolism and body composition and that physical detraining of 4 months could reverse some of the adaptations of physical training.

\section{Methods}

\section{Animals}

Wistar rats (Rattus norvegicus albinus) were used in the present study. The experiment was initiated in 2-month-old animals, and these animals were maintained until 12 months of age. The rats were reared collectively (4 animals per cage) in plastic cages, fed a standard rodent diet (Purina) and provided water ad libitum at an ambient temperature of $25^{\circ} \mathrm{C}$ and a photoperiod of $12 \mathrm{~h}$ of light and dark. The Ethics Committee on Animal Use of the Institute of Biosciences, UNESP, Rio Claro ("Comitê de Ética no uso de Animais do Instituto de Biociências, UNESP, Rio Claro"-CEUA) approved all the procedures performed on animals under protocol 2638.

\section{Design and experimental groups}

The rats were separated into three groups based on the training performed:

Control Group $(n=8)$-not performed to physical training and assessed at 12 months.

Trained Group ( $n=8$ )-performed to physical training at an intensity of $80 \%$ MLSS starting in early adulthood (4 months old), maintained until the end of the study (12 months) and evaluated at 12 months.

Detrained Group $(n=8)$-performed to physical training at an intensity of $80 \%$ MLSS starting in early adulthood (4 months old), lasting 4 months, stopped at 8 months of age and evaluated at 12 months.

\section{Physical training}

Animals in the trained and detrained groups performed swimming exercise in individual water tanks at $30 \pm 2{ }^{\circ} \mathrm{C}$, $1 \mathrm{~h}$ per day, 5 day per week. Lead weights were tied to the rat's chest, which represents $80 \%$ of the load equivalent to aerobic/anaerobic metabolic transition as identified by the MLSS. The MLSS was evaluated every 2 months to readjust the training loads.

\section{Maximal lactate steady state-MLSS}

The MLSS is equivalent to the highest concentration of lactate entry into the blood circulation, which is counterbalanced by lactate removal during exercise under constant loads [23]. MLSS determinations are useful in exercise prescriptions and assessments of aerobic capacity. Our research group recently described a protocol for MLSS 
determinations in rats during swimming exercise [21], and this protocol was used in the present study.

Briefly, the animals performed various swimming tests while supporting constant and increasing exercise loads in relation to their body weight at 48 -h intervals until a stabilization of blood lactate concentrations during the exercise session was no longer possible. Each test included 25 min of continuous swimming while supporting a weight. Blood was collected every $5 \mathrm{~min}$ via a small cut at the tail tip to assess lactate concentrations. Lactate concentrations were determined in a blood lactate analyzer (YSI 1500 Sport, Yellow Springs, OH, USA). The stabilizing criterion was a difference equal to or less than $1.0 \mathrm{mM}$ blood lactate between 10 and $25 \mathrm{~min}$ of exercise.

\section{Body weight}

Body weights were recorded at the end of the experiments using a digital scale.

\section{Glucose tolerance test: GTT}

The GTT was employed to evaluate the glucose tolerance of the animals. This test was performed during the last week of the experiments after a 12-h fast in the first blood collection from a cut at the tail tip (time 0 ). The animals received a $20 \%$ glucose solution ( $2 \mathrm{~g} / \mathrm{kg}$ body weight) via a polyethylene gastric tube. Blood samples were collected after 30,60 and 120 min using heparinized capillaries and were calibrated to $25 \mu \mathrm{L}$ volume for determinations of glucose levels. A single cut at the tail tip was sufficient to collect all blood samples. The glucose-oxidase method determined blood glucose levels. The results were analyzed using the area under the curve of serum glucose during the test by the trapezoidal method in ORIGIN software.

\section{Insulin tolerance test: ITT}

The insulin tolerance test (ITT) evaluated peripheral insulin sensitivity. This test was performed $48 \mathrm{~h}$ after the GTT in the first blood collection from the cut tail tip of the animal (time 0 ). The animals were injected subcutaneously with a crystalline insulin solution (LILLY U 40) at a dose of $30 \mathrm{UI} / 100 \mathrm{~g}$ body weight. Blood samples were collected after 30,60 and 120 min using heparinized capillaries and calibrated to a $25-\mu \mathrm{L}$ volume to determine glucose concentrations via the glucose-oxidase method. A single cut at the tail tip was sufficient to collect all blood samples. The removal rate of glucose (KITT), expressed in $\% / \mathrm{min}$, was calculated using ORIGIN software using a least squares curve analysis of blood glucose levels following insulin administration, during which serum glucose levels decay.

\section{Animal euthanize and collection of biological materials}

The rats were deeply anesthetized with $\mathrm{CO}_{2} 48 \mathrm{~h}$ after the last "in vivo" assessment and were euthanized by decapitation. Blood samples were collected to separate serum and glucose using commercially available kits $\left(\right.$ LABORLAB $\left.^{\circledR}\right)$.

\section{Adipose tissue}

Adipose tissues from the mesenteric, retroperitoneal and posterior subcutaneous regions of the rats were removed for weighing. The excision of different fat deposits was performed according to Cinti et al. [24].

\section{Liver, heart and soleus skeletal muscle}

Portions of the heart, liver and soleus muscle were excised to determine glycogen levels using the method of Dubois et al. [25].

\section{Soleus muscle}

Longitudinal muscle slices weighing approximately 25-35 mg were incubated in Krebs-Ringer bicarbonate medium enriched with glucose $(5.5 \mathrm{mM})$ containing $\left[{ }^{3} \mathrm{H}\right]$ 2-deoxyglucose $(0.5 \mu \mathrm{Ci} / \mathrm{mL}) \quad(2-\mathrm{DG})$ and insulin $(100 \mathrm{mU} / \mathrm{mL})$ in glass vials for approximately $1.5 \mathrm{~h}$ with continuous $\mathrm{O}_{2} / \mathrm{CO}_{2}(95 \% / 5 \%)$ gas under constant stirring in a water bath $\left(37^{\circ} \mathrm{C}\right)$. Glucose uptake was evaluated using the 2-DG as a marker, and radioactivity $\left[{ }^{3} \mathrm{H}\right]$ was measured with the aid of beta particle counter.

\section{Statistics}

The data are expressed as mean and standard deviation. The Shapiro-Wilk $W$ test was used to verify the normality of the sample. The results were analyzed using an analysis of variance (one-way ANOVA) at a pre-set significance level of 5\%. The Newman-Keuls post hoc test was used when necessary. The statistical analyses were performed using Statistic program to windows.

\section{Results}

Table 1 presents the body weight and the weights of mesenteric, retroperitoneal and posterior subcutaneous tissues. Significant differences in body weight and mesenteric tissues were observed. The Trained animals exhibited lower values for these variables. 
Table 1 Mean and standard deviation of body weight $(\mathrm{g})$ and the weights of adipose tissues (mg/g of body weight), including the mesenteric, retroperitoneal and subcutaneous tissues, at the end of the experiment

\begin{tabular}{lllll}
\hline Groups & Body weight & Mesenteric & Retroperitoneal & Subcutaneous \\
\hline Control & $588 \pm 71^{\mathrm{a}}$ & $4399 \pm 643^{\mathrm{a}}$ & $3191 \pm 703$ & $1896 \pm 758$ \\
Trained & $515 \pm 72^{\mathrm{b}}$ & $3007 \pm 811^{\mathrm{b}}$ & $2604 \pm 1112$ & $1635 \pm 188$ \\
Detrained & $576 \pm 62^{\mathrm{a}}$ & $4085 \pm 540^{\mathrm{a}}$ & $3600 \pm 858$ & $1897 \pm 385$ \\
\hline
\end{tabular}

Different letters indicate statistically significant differences- $\mathrm{a} \# \mathrm{~b}$ (one-way ANOVA and Newman-Keuls post hoc test, $p<0.05$ )

Table 2 Mean and standard deviation of glucose values $(\mathrm{mg} /$ $\mathrm{dL})$ and the area under the glucose curve (mg/dL $120 \mathrm{~min})$ during the glucose tolerance test

\begin{tabular}{llllll}
\hline Groups & T0 & T30 & T60 & T120 & Area under the curve \\
\hline Control & $82 \pm 6^{\mathrm{a}}$ & $99 \pm 12^{\mathrm{a}}$ & $117 \pm 8^{\mathrm{a}}$ & $95 \pm 12$ & $12314 \pm 1122^{\mathrm{a}}$ \\
Trained & $53 \pm 6^{\mathrm{b}}$ & $71 \pm 7^{\mathrm{b}}$ & $77 \pm 9^{\mathrm{b}}$ & $75 \pm 6$ & $8428 \pm 853^{\mathrm{b}}$ \\
Detrained & $62 \pm 10^{\mathrm{b}}$ & $79 \pm 10^{\mathrm{b}}$ & $82 \pm 16^{\mathrm{b}}$ & $82 \pm 10$ & $9433 \pm 1200^{\mathrm{b}}$ \\
\hline
\end{tabular}

Different letters indicate statistically significant differences-a \# b (one-way ANOVA and Newman-Keuls post hoc test, $p<0.05$ )
Table 2 presents the values of blood glucose and the area under the glucose curve during the GTT. Control animals exhibited a larger area under the glucose curve than did the other groups. The detrained animals tended to display larger areas than did the trained group.

Table 3 presents the values of blood glucose and the glucose removal constant (KITT) during the ITT. No statistically significant differences were observed between groups.

The following values of the exercise loads relative to body weight $(\%)$ for the MLSS were observed: Control $4.6 \pm 0.4$, Trained $5.8 \pm 1.3$, Detrained $5.3 \pm 0.4$. The control animals exhibited a lower exercise load relative to the body weight (\%) in the MLSS compared to Trained and Detrained animals.

No significant differences in the values of serum glucose were observed (Table 4). However, statistically significant differences in muscle glycogen levels in the soleus muscle, liver and heart were observed (Table 4). Trained animals exhibited higher glycogen concentrations compared to Control and Detrained animals. Table 4 presents the glucose uptake values of the isolated soleus muscles. The

Table 3 Mean and standard deviation of glucose values $(\mathrm{mg} / \mathrm{dL})$ and glucose removal constant (KITT_\%/min) during the insulin tolerance test

\begin{tabular}{llllrl}
\hline Groups & T0 & T30 & \multicolumn{1}{l}{ T60 } & \multicolumn{1}{l}{ T120 } & \multicolumn{1}{l}{ KITT } \\
\hline Control & $103 \pm 6$ & $85 \pm 8$ & $90 \pm 11$ & $119 \pm 16$ & $0.66 \pm 0.18$ \\
Trained & $102 \pm 6$ & $89 \pm 10$ & $89 \pm 10$ & $92 \pm 13$ & $0.62 \pm 0.24$ \\
Detrained & $110 \pm 7$ & $99 \pm 10$ & $91 \pm 23$ & $104 \pm 26$ & $0.56 \pm 0.26$
\end{tabular}

There are no statistically significant differences among groups (oneway ANOVA $p<0.05$ )
Trained and Detrained groups exhibited higher values than the Control group.

\section{Discussion}

Physical exercise that is performed in a controlled manner (e.g., with a specific frequency, volume and intensity) provides several benefits to the organism, such as disease control and improvements in aerobic capacity. Improved physical fitness is expected using a systematic program of physical training [10, 26, 27].

The main results of this study are that the physical training in middle-age animals protected against the increase in the body weight and visceral fat depots, caused by aging, as well as increased muscle glycogen content. However, it is the necessary maintenance of this training, because this effect was abolished by physical deconditioning. Additionally, the physical training prevented the decrease in the glucose tolerance and muscle glucose uptake due to aging and this effect was maintained after physical detraining.

Decreases in body weight and the weight of mesenteric adipose tissues were observed in the Trained group, which is consistent with previous results reported in the literature $[28,29]$. The increase of fat in the mesenteric region is closely linked to insulin resistance and other metabolic disorders [30, 31]. The Detrained animals exhibit similar body weight as compared with the control group, possibly because these animals remained inactive for 4 months, which supports a reduction in calorie expenditure compared to the Trained group.

The body weight reduced in mice C57BL/6 trained for 4 weeks and this alteration was reversed after 2 weeks of physical detraining. The lipolytic activity stimulated by 
Table 4 Mean and standard deviation of serum glucose ( $\mathrm{mg} / \mathrm{dL})$, heart, liver and muscle glycogen ( $\mathrm{mg} / 100 \mathrm{mg})$ and glucose uptake by isolated soleus muscles $(\mu \mathrm{mol} / \mathrm{g} / \mathrm{h})$

\begin{tabular}{llllll}
\hline Groups & Serum glucose & Heart glycogen & Liver glycogen & Muscular glycogen & Glucose uptake \\
\hline Control & $157 \pm 26$ & $0.06 \pm 0.01$ & $6.04 \pm 0.68$ & $0.48 \pm 0.07^{\mathrm{b}}$ & $1.96 \pm 0.54^{\mathrm{b}}$ \\
Trained & $140 \pm 24$ & $0.06 \pm 0.01$ & $6.12 \pm 0.35$ & $0.66 \pm 0.18^{\mathrm{a}}$ & $3.28 \pm 0.53^{\mathrm{a}}$ \\
Detrained & $154 \pm 17$ & $0.07 \pm 0.01$ & $6.16 \pm 1.00$ & $0.46 \pm 0.10^{\mathrm{b}}$ & $2.55 \pm 0.35^{\mathrm{a}}$ \\
\hline
\end{tabular}

Different letters indicate statistically significant differences- $\mathrm{a} \# \mathrm{~b}$ (one-way ANOVA and Newman-Keuls post hoc test, $p<0.05$ )

citrate synthase activity increased in trained group, but was reversed by detraining [28]. Therefore, physical exercise must be maintained throughout the life of the individual to maintain metabolic adaptations, such as increases in basal metabolism.

Physical training did not modify serum glucose levels. Physical exercise does not improve glucose levels in elderly normoglycemic individuals, but exercise effectively lowers glycemia in elderly pre-diabetics [32]. On the other hand, the reduction in the area under the glucose curve in Trained animals is an important adaptation because smaller values on the glucose curve during the GTT indicate an improved body response to glucose exposure (hyperglycemia) in which the glucose absorption into the bloodstream is more efficient. Therefore, exercise prevents glucose intolerance, which is extremely important because glucose intolerant individuals exhibit an increased risk (11\%/year) of developing type-2 diabetes compared to normal individuals [33]. Exercise also decreases glucose intolerance [34-36].

Insulin sensitivity is not altered in any of the experimental groups, suggesting that the improvements in glucose tolerance were due to changes in the translocation of glucose transport (GLUT)-containing vesicles from the cytoplasm to the cell membrane. This translocation increases the intracellular entry of glucose. Hypertensive animals trained for 10 weeks showed an increased expression of GLUT-4 [37].

Control animals exhibited a lower MLSS workload compared to the Trained and Detrained groups, which corroborates previous studies [38, 39]. Interestingly, the Detrained animals exhibited a relative MLSS workload that was greater than the Controls, but this value was reduced compared to the Trained animals. These results suggest that the adaptations in this parameter persisted until the end of the experiment.

Lo et al. demonstrated that individuals who trained aerobically for a period of time and were subsequently maintained for 24 weeks without training (i.e., "detrained") lost the achieved adjustments with training and exhibited an increase in body weight and reductions in $V \mathrm{O}_{2 \max }$ [40]. Other studies [29, 41-45] have argued that detraining produced losses in aerobic capacity, altered body composition and decreased basal metabolism. These results are observed in athletes and healthy adults with physical restrictions.

Exercise effectively increased muscle glycogen stores in trained animals in the present study. However, the muscle glycogen levels in Detrained animals were similar to the Control animals at the end of the experiment due to the long period of detraining. This result confirms the findings of Pauli et al. [31] who also observed an increase in muscle glycogen in animals subjected to physical training for 10 weeks. These results are also similar to previous studies $[10,15]$. Muscle glycogen stores are important in the performance of prolonged exercise because this substrate is required for muscle contractions [14].

However, physical training did not alter glycogen deposits in the liver and the heart, which suggests that the GLUTs in hepatocytes, cardiac myocytes and muscle cells are distinct, and the adaptations to exercise may be different.

Glucose is an important substrate for the performing of muscular work, and differences in Glucose muscular metabolism between trained, detrained and control (sedentary) animals should be discussed. Therefore, glucose uptake in incubated soleus muscle was evaluated. Trained animals exhibited an increased glucose uptake compared to the Detrained and Control animals, which suggested that regular exercise exerts a beneficial effect on glucose uptake [20]. Previous studies have also demonstrated that physical exercise, including acute activity, increases the phosphorylation of the insulin receptor, which enhances glucose uptake in elderly animals [30].

Therefore, physical exercise at submaximal $(80 \%$ of MLSS) intensities induced important changes in rats at middle age, such as reductions in body weight and the weight of mesenteric adipose tissue and increases in the exercise load, as measured by MLSS intensity, glucose tolerance, deposits of muscular glycogen and glucose uptake by skeletal muscle in Trained animals. However, only the alterations at aerobic capacity, glucose tolerance and muscle glucose uptake were maintained after detraining. Physical exercise with submaximal characteristics is 
more attractive and easily adopted by the healthy population and individuals with metabolic disorder.

Acknowledgements We are grateful to the São Paulo Research Foundation (FAPESP Process No. 2010/12896-0). We thank José Roberto R. Silva for technical assistance. This manuscript was translated for proper English Language by native speaking editors at American Journal Experts.

\section{Compliance with ethical standards}

Conflict of interest The authors declare that they have no competing interests.

Ethical approval All procedures performed in studies were in accordance with the ethical standards of the institutional and/or national research committee. All procedures were approved by the University Research Ethics Committee.

Informed consent For this type of study, formal consent is not required.

\section{References}

1. Mazur-Bialy AI, Pocheć E (2017) Vitamin B2 deficiency enhances the pro-inflammatory activity of adipocyte, consequences for insulin resistance and metabolic syndrome development. Life Sci 178:9-16

2. Xu H, Barnes GT, Yang Q, Tan G, Yang D, Chou CJ et al (2003) Chronic inflammation in fat plays a crucial role in the development of obesity-related insulin resistance. J Clin Invest 112(12):1821-1830

3. Weisberg SP, McCann D, Desai M, Rosenbaum M, Leibel RL, Ferrante AW (2003) Obesity is associated with macrophage accumulation in adipose tissue. J Clin Invest 112(12):1796-1808

4. Andersen CJ, Murphy KE, Fernandez ML (2016) Impact of obesity and metabolic syndrome on immunity. Adv Nutr 7(1):66-75

5. Rocha-Rodrigues S, Rodríguez A, Gonçalves IO, Moreira A, Maciel E, Santos S et al (2017) Impact of physical exercise on visceral adipose tissue fatty acid profile and inflammation in response to a high-fat diet regimen. Int $\mathrm{J}$ Biochem Cell Biol $87: 114-124$

6. Botezelli JD, Mora RF, Dalia RA, Moura LP, Cambri LT, Ghezzi $\mathrm{AC}$ et al (2010) Exercise counteracts fatty liver disease in rats fed on fructose-rich diet. Lipids Health Dis 9:116

7. Botezelli JD, Cambri LT, Ghezzi AC, Dalia RA, Scariot PP, Ribeiro C et al (2011) Different exercise protocols improve metabolic syndrome markers, tissue triglycerides content and antioxidant status in rats. Diabetol Metab Syndr 3:35

8. Liu S, Du F, Li X, Wang M, Duan R, Zhang J, Wu Y, Zhang Q (2017) Effects and underlying mechanisms of irisin on the proliferation and apoptosis of pancreatic $\beta$ cells. PLoS One 10:12

9. Issurin V (2008) Block periodization versus traditional training theory: a review. J Sports Med Phys Fit 48:65-75

10. de Araujo GG, Papoti M, Dos Reis IG, de Mello MA, Gobatto CA (2012) Physiological responses during linear periodized training in rats. Eur J Appl Physiol 112:839-852

11. Hayes JP, Chappell MA (1990) Individual consistency of maximal oxygen consumption in deer mice. Funct Ecol 4:495-503

12. Xie B, Yan X, Cai X, Li J (2017) Effects of high-intensity interval training on aerobic capacity in cardiac patients: a systematic review with meta-analysis. Biomed Res Int 2017:5420840

13. Carmeli E, Merrick J, Kessel S, Masharawi Y, Carmeli V (2003) Elderly persons with intellectual disability: a study of clinical characteristics, functional status, and sensory capacity. Sci World J 3:298-307

14. Bergstrom J, Hermansen L, Hultman E, Saltin B (1967) Diet, muscle glycogen and physical performance. Acta Physiol Scand $71: 140-150$

15. Ghanbari-Niaki A, Kraemer RR, Abednazari H (2011) Timecourse alterations of plasma and soleus agouti-related peptide and relationship to ATP, glycogen, cortisol, and insulin concentrations following treadmill training programs in male rats. Horm Metab Res 43(2):112-116

16. Jensen J, Lai YC (2009) Regulation of muscle glycogen synthase phosphorylation and kinetic properties by insulin, exercise, adrenaline and role in insulin resistance. Arch Physiol Biochem 115(1):13-21

17. Jensen TE, Richter EA (2012) Regulation of glucose and glycogen metabolism during and after exercise. J Physiol 590(5):1069-1076

18. Jensen J, Rustad PI, Kolnes AJ, Lai YC (2011) The role of skeletal muscle glycogen breakdown for regulation of insulin sensitivity by exercise. Front Physiol 2:112

19. Sjøberg KA, Frøsig C, Kjøbsted R, Sylow L, Kleinert M, Betik AC et al (2017) Exercise increases human skeletal muscle insulin sensitivity via coordinated increases in microvascular perfusion and molecular signaling. Diabetes 66(6):1501-1510

20. Luciano E, Carneiro EM, Carvalho CR, Carvalheira JB, Peres SB, Reis MA et al (2002) Endurance training improves responsiveness to insulin and modulates insulin signal transduction through the phosphatidylinositol 3-kinase/Akt-1 pathway. Eur J Endocrinol 147(1):149-157

21. Gobatto CA, de Mello MA, Sibuya CY, de Azevedo JR, dos Santos LA, Kokubun E (2001) Maximal lactate steady state in rats submitted to swimming exercise. Comp Biochem Physiol A Mol Integr Physiol 130(1):21-27

22. Pavlik G (1985) Effects of physical training and detraining on resting cardiovascular parameters in albino rats. Acta Physiol Hung 66(1):27-37

23. Heck H, Mader A, Hess G, Mücke S, Müller R, Hollmann W (1985) Justification of the 4-mmol/l lactate threshold. Int J Sports Med 6(3):117-130

24. Cinti S, Mitchell G, Barbatelli G, Murano I, Ceresi E, Faloia E et al (2005) Adipocyte death defines macrophage localization and function in adipose tissue of obese mice and humans. J Lipid Res 46(11):2347-2355

25. Dubois M, Gilles KA, Hamilton JK, Rebers PA, Smith F (1956) Colorimetric method for determination of sugars and related substances. Anal Chem 28:350-356

26. Franchini E, Branco BM, Agostinho MF, Calmet M, Candau R (2015) Influence of linear and undulating strength periodization on physical fitness, physiological, and performance responses to simulated judo matches. J Strength Cond Res 29(2):358-367

27. Prestes J, da Cunha Nascimento D, Tibana RA, Teixeira TG, Vieira DC, Tajra V et al (2015) Understanding the individual responsiveness to resistance training periodization. Age (Dordr) 37(3):9793

28. Mazzucatto F, Higa TS, Fonseca-Alaniz MH, Evangelista FS (2014) Reversal of metabolic adaptations induced by physical training after two weeks of physical detraining. Int J Clin Exp Med 7(8):2000-2008

29. Ormsbee MJ, Arciero PJ (2011) Detraining increases body fat and weight and decreases $V \mathrm{O}_{2}$ peak and metabolic rate. J Strength Cond Res 26(8):2087-2095 
30. Pauli JR, Ropelle ER, Cintra DE, De Souza CT, da Silva AS, Moraes JC et al (2010) Acute exercise reverses aged-induced impairments in insulin signaling in rodent skeletal muscle. Mech Ageing Dev 131(5):323-329

31. Pauli JR, Leme J, Crespilho D, Mello MA, Rogatto G, Luciano E (2005) Influence of physical training on the parameters of the adrenal hypothalamic pituitary axis of rats treated with dexamethasone. Rev Port Cien Desp 2:143-152

32. Geirsdottir OG, Arnarson A, Briem K, Ramel A, Jonsson PV, Thorsdottir I (2012) Effect of 12-week resistance exercise program on body composition, muscle strength, physical function, and glucose metabolism in healthy, insulin-resistant, and diabetic elderly Icelanders. J Gerontol A Biol Sci Med Sci 67(11):1259-1265

33. Knowler WC, Barrett-Connor E, Fowler SE, Hamman RF, Lachin JM, Walker EA et al (2002) Reduction in the incidence of type 2 diabetes with lifestyle intervention or metformin. N Engl $\mathrm{J}$ Med 346(6):393-403

34. Barbosa de Queiroz K, Honorato-Sampaio K, Rossoni Júnior JV, Andrade Leal D, Pinto AB, Kappes-Becker L et al (2017) Physical activity prevents alterations in mitochondrial ultrastructure and glucometabolic parameters in a high-sugar diet model. PLoS One 12(2):e0172103

35. Farah D, Nunes J, Sartori M, Dias DD, Sirvente R, Silva MB et al (2016) Exercise training prevents cardiovascular derangements induced by fructose overload in developing rats. PLoS One 11(12):e0167291

36. Fidalgo M, Falcão-Tebas F, Bento-Santos A, de Oliveira E, Nogueira-Neto JF, de Moura EG et al (2013) Programmed changes in the adult rat offspring caused by maternal protein restriction during gestation and lactation are attenuated by maternal moderate-low physical training. $\mathrm{Br} \quad \mathrm{J}$ Nutr 109(3):449-456

37. Marschner RA, Pinto G, Borges J, Markoski MM, Schaan BD, Lehnen AM (2017) Short-term detraining does not change insulin sensitivity and RBP4 in rodents previously submitted to aerobic exercise. Horm Metab Res 49(1):58-63

38. Santos AP, Marinho DA, Costa AM, Izquierdo M, Marques MC (2012) The effects of concurrent resistance and endurance training follow a detraining period in elementary school students. J Strength Cond Res 26(6):1708-1716

39. Ferreira JC, Rolim NP, Bartholomeu JB, Gobatto CA, Kokubun E, Brum PC (2007) Maximal lactate steady state in running mice: effect of exercise training. Clin Exp Pharmacol Physiol 34(8):760-765

40. Lo MS, Lin LL, Yao WJ, Ma MC (2011) Training and detraining effects of the resistance vs. endurance program on body composition, body size, and physical performance in young men. J Strength Cond Res 25(8):2246-2254

41. Theodorou AA, Panayiotou G, Volaklis KA, Douda HT, Paschalis V, Nikolaidis MG et al (2016) Aerobic, resistance and combined training and detraining on body composition, muscle strength, lipid profile and inflammation in coronary artery disease patients. Res Sports Med 24(3):171-184

42. Mitsuhashi T, Yamada C, Iida A, Hiratsuka N, Inabe F, Araida N et al (2011) Long-term detraining increases the risk of metabolic syndrome in Japanese men. Tokai J Exp Clin Med 36(4):95-99

43. Vogler CM, Menant JC, Sherrington C, Ogle SJ, Lord SR (2012) Evidence of detraining after 12 -week home-based exercise programs designed to reduce fall-risk factors in older people recently discharged from hospital. Arch Phys Med Rehabil 93(10): 1685-1691

44. Coetsee C, Terblanche E (2015) The time course of changes induced by resistance training and detraining on muscular and physical function in older adults. Eur Rev Aging Phys Act 12:7

45. Joo CH (2016) The effects of short-term detraining on exercise performance in soccer players. J Exerc Rehabil 12(1):54-59 